\title{
Jakub OsIecki
}

(D) https://orcid.org/0000-0002-1339-0568

Ośrodek Badań nad Kulturą Ormiańską w Polsce

Polska Akademia Umiejętności

\section{OMÓWIENIE WYBRANYCH ANGIELSKOJĘZYCZNYCH PUBLIKACJI ARMENISTYCZNYCH Z ROKU 2020}

\begin{abstract}
Abstrakt: Artykuł stanowi omówienie kilku wybranych publikacji armenistycznych wydanych w języku angielskim w 2020 roku. Przedstawione zostały wydawnictwa książkowe, które ukazały się przede wszystkim nakładem wydawnictwa I. B. Tauris (Bloomsbury Publishing), amerykańskiego stowarzyszenia Society for Armenian Studies, a także domów wydawniczych Brill i Peter Lang.
\end{abstract}

Słowa kluczowe: Armenia, armenistyka

W roku 2020 ukazało się wiele wartościowych publikacji z zakresu armenistyki. Nie sposób omówić wszystkich, zatem dokonałem subiektywnego wyboru tych, które moim zdaniem wydają się najciekawsze.

W ramach Armenian Publication Series wyszło drukiem kilka prac wartych zarekomendowania. Sa to: The Complete. Lyrics. Poems Misaka Medzarenca w tłumaczeniu z języka ormiańskiego na angielski Jamesa R. Russella, dzieło autorskie The Armenians of Musa Dagh. From Obscurity to Genocide Resistance and Fame 1840-1915 Vahrama L. Shemmassiana, oraz dwa zbiory artykułów Armenians and Kurds in the Late Ottoman Empire, pod redakcją Ümita Kurta i Ary Sarafiana, i The First Armenian Republic (1918-1920) on its Centenary. Politics, Gender and Diplomacy, pod redakcją Bedrossa Der Matossiana. Widać wyraźnie, że tematyka podejmowana w tych publikacjach Society for Armenian Studies jest bardzo współczesna i obejmuje przede wszystkim schyłek 
wieku XIX i pierwszą połowę XX. Osią licznych publikacji wydawanych w USA niezmiennie pozostaje ludobójstwo Ormian.

Pierwsza pozycja zawiera wszystkie wiersze Misaka Medzarenca (Uhuup Utiduplifg), neoromantycznego poety ormiańskiego, który zmarł w wieku zaledwie 22 lat. Medzarenc, a właściwie Medzaturian (Ułouunnıpjuu), urodził się 19 stycznia 1889 roku w niewielkiej wsi Benka w wilajecie Harputu, w Turcji. Następnie wraz z rodziną przeniósł się jako mały chłopiec do Sebastii i Marzwanu (Merzifonu), by ostatecznie zamieszkać w Stambule (Polis w nazewnictwie ormiańskim). Zadebiutował w wieku 15 lat, publikując wiersz $\mathrm{w}$ jednej z lokalnych gazet. W roku 1905 ukończył liceum ormiańskie przy kościele św. Grzegorza Oświeciciela w Galacie, a w dwa lata później ukazał się jego pierwszy tomik wierszy Tęcza (Ōhuduud) wydany w stolicy imperium osmańskiego. Medzarenc uważany jest za jednego z najwybitniejszych poetów Zachodniej Armenii. Jego twórczość była przedmiotem licznych badań i analiz literackich - szczególnie wśród literaturoznawców z diaspory ormiańskiej. Przetłumaczenia z języka zachodnioormiańskiego i omówienia twórczości Medzarenca podjął się James R. Russell, emerytowany profesor uniwersytetu Harvarda, wieloletni pracownik Instytutu Armenistyki na Wydziale Studiów Bliskowschodnich. The Complete. Lyric. Poems to pierwsze całościowe ujęcie twórczości Medzarenca w języku angielskim, które zawiera 180 utworów lirycznych w oryginale i w tłumaczeniu. Stanowi kontynuację wcześniejszych zainteresowań poezją prof. Russella. Kilka lat wcześniej ukazała się książka Bosphorus Nights (Noce nad Bosforem), przekład na język angielski wierszy Bedrosa Touriana - innego wielkiego poety zachodniej Armenii. Na język polski kilka wierszy Medzarenca zostało przetłumaczonych z języka oryginalnego przez Jerzego Szokalskiego i zamieszczonych w zbiorze Poezja armeńska. Antologia ${ }^{1}$, który ukazał się przed wielu laty w ramach serii Poezja narodów Związu Radzieckiego.

Tom pod tytułem Armenians and Kurds in the Late Ottoman Empire (red. Ü. Kurt i A. Sarafian) zawiera pięć artykułów, będących pokłosiem konferencji „Armenians, Greeks, and Kurds. A People's History of the Ottoman Empire”, zorganizowanej we wrześniu 2017 roku na uniwersytecie stanowym Kalifornii Fresno (USC Fresno). Pierwsze trzy studia dotyczą lat 1894-1896, które w historii imperium osmańskiego dla Ormian kojarzą się jednoznacznie z tzw. masakrami hamidiańskimi (nazwa wywodzi się od inicjatora pogromów, krwawego sułtana Abdula Hamida II). Owen Miller w artykule pod tytułem Uplands, Lowlands, and Mass Violence in Ottoman Cilicia zaprezentował swoje badania dotyczące prześladowań Ormian w Armenii Cylicyjskiej (przede wszystkim w Zejtunie). Ümit Kurt szeroko omówił jeden z raportów ostatniego katolikosa Ahtamar, Cha-

${ }^{1}$ Poezja armeńska. Antologia, wybór: A. Szymański i P. Kuncewicz, wstęp: A. Szymański, Łódź 1984. 
czatura II, który w 1895 zrelacjonował mordy na Ormianach popełnione w okolicach jeziora Wan. O relacjach ormiańsko-kurdyjskich w końcowych latach XIX wieku traktuje artykuł Emre Can Dağlıoğlu, a Nilay Özok-Gündoğan podjęła się trudnego zadania historiograficznego ujęcia relacji ormiańsko-kurdyjskich w kontekście badań bliskowschodnich. Ostatni z artykułów, autorstwa Varaka Ketsemaniana (Ideologies Paradoxes, and Fedayis in the Late Ottoman Empire. Historiographical Challenges and Methodological Problems in the Study of the Armenian Revolutionary Movement, 1890-1896), to ważne krytyczne spojrzenie na historię Armenii Zachodniej, redefiniujące ormiański ruch rewolucyjny w imperium osmańskim.

Na pracę zbiorową pod tytułem The First Armenian Republic (1918-1920) on its Centenary. Politics, Gender and Diplomacy składają się artykuły Richarda Hovhannisiana, Bedrossa Der Matossiana, Houri Berberian, Ariego Şekeryana, Sedy D. Ohanian, Rubiny Peroomian, Vartana Matossiana, Garabeta K. Moumdjana, George'a Bournoutiana oraz Jakuba Osieckiego. Niewątpliwie wart polecenia jest artykuł wstępny pióra prof. Hovhannisiana - autora czterotomowego dzieła The Republic of Armenia ${ }^{2}$ (Los Angeles 1971, 1982, 1996, 1996). Do dziś jego dorobek naukowy jest najbardziej komplementarnym źródłem wiedzy o historii Armenii w latach 1918-1920, opartym na gigantycznym materiale źródłowym. Jego artykuł w omawianej publikacji jest kompendium dotyczącym wspomnianego okresu. Z kolei artykuł młodego naukowca Ari Şekeryana zawiera prezentację jednego $\mathrm{z}$ wątków jego pracy doktorskiej pod tytułem The Armenians in the Ottoman Empire after the First World War (1918-1923), obronionej na Uniwersytecie Oxfordzkim w 2018 roku. Przedstawił w nim obraz tureckiej prasy w roku 1918, w której, co dość zaskakujące, elity tureckie z entuzjazmem przyjęły ogłoszenie niepodległości Armenii. Ten pozytywny stosunek zmienił się jednak dość szybko, gdy władze w Erywaniu zadeklarowały, że chcą powiększyć swoje zakaukaskie terytorium o ziemie należące do Turcji. Ciekawe wnioski zaprezentował w swoim artykule prof. George Bournoutian (The Unrealistic Territorial Demands of the Armenian Republic 1919-1920). Autor sugeruje, że Armenia, rządzona w latach 1918-1920 w znacznym stopniu przez dasznaków (Dasznakcutiun), miałaby większe szanse na ocalenie, gdyby stosunkowo wcześnie podjęła rozmowy z bolszewikami. Całkowite zarzucenie negocjacji z nimi było zdaniem prof. Bournoutiana posunięciem niedojrzałym dyplomacji ormiańskiej. Jakub Osiecki, wykorzystując materiały watykańskiego Archivio Storico della Segreteria di Stato di Sua Santità, przedstawił próby nawiązania relacji dyplomatycznych pomiędzy Republiką Armenii a Stolicą Apostolską. Tekst traktuje o wizycie o. Antoine'a Delpucha ze zgromadzenia Ojców Białych (jednego z założycieli rzymskiego Pontificio Istituto Orientale), który odwiedził w 1919 roku Zakaukazie.

\footnotetext{
2 R. Hovhannisian, The Republic of Armenia, Los Angeles 1971, 1982, 1996, 1996.
} 
Ostatnia ze wspomnianych publikacji Armenian Publication Series to całościowe ujęcie losów Ormian z sześciu wsi skupionych wokół Musa Dagh. Doktor Shemmassian w pracy The Armenians of Musa Dagh. From Obscurity to Genocide Resistance and Fame 1840-1915 opisał tę wspólnotę na kilku płaszczyznach: ekonomicznej, religijnej, politycznej. Celem tej analizy była próba odpowiedzi na pytanie, co wpłynęło na to, iż mieszkańcy tego regionu tak doskonale zorganizowali oddziały samoobrony i byli w stanie odeprzeć ataki oddziałów tureckich. Do dziś potomkowie ocalałych z Musa Dagh żyją w mieście Andżar w dolinie Bekaa, w Libanie.

W roku 2018 londyńsko-nowojorski dom wydawniczy I. B. Tauris, zajmujący się od wielu lat tematyką ormiańską i bliskowschodnią, stał się częścią brytyjskiego wydawnictwa o zasięgu globalnym Bloomsbury Publishing. Równocześnie powołano do istnienia dział publikacji armenistycznych w Bloomsbury. W minionym roku ukazały się w nim dwie książki: The Armenian Experience. From Ancient Times to Independence, Gaidza Minassiana, oraz When We Dead Awaken. Australia, New Zealand and Armenian Genocide.

Druga $\mathrm{z}$ tych publikacji to dzieło brytyjskiego historyka i dziennikarza Jamesa Robinsa. Autor jest twórcą podcastu „Great Crime”, poświęconego ludobójstwu Ormian. Jego książka to opowieść wykorzystująca materiał archiwalny oraz wspomnienia i relacje żołnierzy korpusu australijsko-nowozelandzkiego (ANZAC), którzy znaleźli się jako jeńcy wojenni w imperium osmańskim w 1915 roku, po bitwie pod Galipoli, w dzień po pamiętnym 24 kwietnia 1915 (symboliczna data wyznaczająca ludobójstwo Ormian). Robins sięgnął więc po przekaz pochodzący od bezpośrednich świadków dramatycznych wydarzeń. Australijscy i nowozelandzcy żołnierze widzieli transporty i marsze śmierci, a ich raporty po dziś dzień pozostawały nieznane. Robins ukazuje ich treść na tle działań wojennych, w których brały udział wojska ANZAC, i losów żołnierzy tej formacji po zakończeniu pierwszej wojny światowej.

Brokers of Faith, Brokers of Empire. Armenians and the Politics of Reform in the Ottoman Empire to z kolei praca Richarda Antaramiana, której celem, jak się wydaje, jest pokazanie, iż sprawne funkcjonowanie imperium osmańskiego w dużym stopniu uzależnione było od roli i zaangażowania wielu religijnych grup mniejszościowych, w tym przypadku - Ormian. Autor koncentruje się przede wszystkim na pozycji duchowieństwa apostolskiego Kościoła ormiańskiego w okresie tanzymatu (reform państwa osmańskiego zainicjowanych w 1839 roku). Prezentuje wielość postaw Ormian wobec centralizacyjnych zmian ustroju państwa oraz ukazuje stanowisko duchowieństwa ormiańskiego, które traktowało zmiany polityczne jako potencjalną możliwość poprawy statusu społecznego Ormian w imperium osmańskim. Wykorzystał w tym celu źródła ormiańskie, tureckie i angielskie. W pięciu rozdziałach (Konstytucja, Diecezja osmańska, Peryferyzacja, Osmanizacja, Katastroficzny sukces) zawarł analizę społeczno- 
-politycznej pozycji Ormian i Kościoła ormiańskiego w XVIII i XIX wieku i scharakteryzował napięcia wokół funkcjonowania dwóch jurysdykcji i dwóch hierarchów kościelnych: patriarchatu konstantynopolitańskiego i katolikosatu Sis. Autor szczegółowo omówił konstytucję ormiańską z 1860 roku, starając się udowodnić, że dokument ten w równym stopniu zreorganizował wspólnotę ormiańską, co wzmocniło tendencje centralizacyjne w imperium.

W roku 2020 w wydawnictwie Peter Lang (Nowy Jork) ukazała się książka autora niniejszego omówienia pod tytułem The Armenian Church in Soviet Armenia. The Policies of the Armenian Bolsheviks and the Armenian Church, 19201932. Jest to publikacja poświęcona prześladowaniom Kościoła ormiańskiego przez reżim sowiecki, pierwsza w języku angielskim na ten temat ${ }^{3}$.

Wspomniany już prof. George Bournoutian ${ }^{4}$ wydał w 2020 roku w wydawnictwie Brill opracowanie historyczne pod tytułem From the Kur to the Aras. A Military History of Russia's Move into the South Caucasus and the First Russo-Iranian War, 1801-1813. Jak pisze we wstępie, jego zamiarem było ostateczne obalenie mitów, które pojawiły się w XIX i na początku XX wieku w związku z konfliktami zbrojnymi pomiędzy Rosją carską a Persją. Rosjanie w kontekście wojen portretowani byli w źródłach irańskich jako żądni krwi muzułmańskiej najeźdźcy, którzy wygrali wojnę o Kaukaz Południowy głównie dzięki zdradzie lokalnych chanów, optujących za Rosją. Z kolei rosyjska historiografia zazwyczaj ukazywała podbój Kaukazu jako narzędzie konieczne do wyzwalania małych narodów, tłamszonych przez jarzmo perskie. Te generalizacje, jakkolwiek czasami niezbędne do powierzchownego zrozumienia historii, $\mathrm{w}$ tym przypadku są zdaniem autora nieprawdziwe. Udowadnia on swą tezę, sięgając po materiały perskie i rosyjskie. Bibliografia źródłowa tej publikacji jest ogromna, obejmuje materiał zgromadzony w Teheranie, Moskwie i Tbilisi, a wkład pracy autora gigantyczny. Wartością dodaną książki są liczne mapy i szkice, które pozwalają w pełni zrozumieć kampanię wojenną, trwającą ponad dziesięć lat. George Bournoutian sporo miejsca poświęca również traktatowi zawartemu w Gulistanie, który zakończył konflikt w roku 1813 . Był to pierwszy traktat persko-rosyjski, który normalizował przebieg granicy między imperiami.

Ostatnia z omawianych tutaj publikacji nie ma charakteru naukowego. Jest to zbiór wspomnień Armenia mon Amour. Ten European Speak, wydanych nakładem wydawnictwa Nineveh. Jej spiritus movens był prof. Svante Lundgren, pracujący na co dzień na Uniwersytecie w Lund (Szwecja). Autor, który w 2019 roku był gościem Ośrodka Badań nad Kulturą Ormiańską w Polsce, zaprosił do współpracy dziesięciu naukowców, których zadaniem było podzielenie się

${ }^{3}$ Praca ta wydana była wcześniej w języku polskim przez Księgarnię Akademicką pod tytułem Bolszewicy a Kościół ormiański (Kraków 2016). Na język angielski przetłumaczyli ją Paweł Siemianowski i Artur Zwolski.

${ }^{4}$ Profesor George Bournoutian zmarł 22 sierpnia 2021 roku. 
osobistymi doświadczeniami w kontaktach z Armenią. Wśród nich znaleźli się językoznawcy, historycy, socjolodzy, religioznawcy: Harald Bothner (Norwegia), Bernard Coulie (Belgia), Frank Engel (Luksemburg), Bálint Kovács (Węgry), Svante Lundgren (Szwecja), Jakub Osiecki (Polska), Stephen Pound (Wielka Brytania), Kate Royster (Dania), Silvia Schmid (Niemcy) i Serafim Seppälä (Finlandia). Ich teksty to wspomnienia i eseje, których tłem pozostaje Armenia.

\section{Bibliografia}

Antaramian R., Brokers of Faith, Brokers of Empire. Armenians and the Politics of Reform in the Ottoman Empire, Stanford 2020 (publikacja dostępna dla czytelników w bibliotece OBKOP), https://doi.org/10.1515/9781503612969

Armenia mon Amour. Ten European Speak, red. S. Lundgren, Enschede 2020 (publikacja dostępna dla czytelników w bibliotece OBKOP)

Armenians and Kurds in the Late Ottoman Empire, red. Ü. Kurt, A. Sarafian, Fresno 2020 Bournoutian G., From the Kur to the Aras. A Military History of Russia's Move into the South Caucasus and the First Russo-Iranian War, 1801-1813, Leiden 2020, https:// doi.org/10.1163/9789004445161

Hovhannisian R., The Republic of Armenia, Los Angeles 1971, 1982, 1996, 1996

Medzarents M., The Complete Lyric Poems, oprac. i tłum. J. Russell, Fresno 2020

Minassian G., The Armenian Experience. From Ancient Times to Independence, LondonNew York 2020, https://doi.org/10.5040/9780755600700

Osiecki J., Bolszewicy a Kościót ormiański, Kraków 2016

Osiecki J., The Armenian Church in Soviet Armenia. The Policies of the Armenian Bolsheviks and the Armenian Church, 1920-1933, New York 2020 (publikacja dostępna dla czytelników w bibliotece OBKOP), https://doi.org/10.3726/b15660

Poezja armeńska. Antologia, wybór A. Szymański i P. Kuncewicz, wstęp A. Szymański, Łódź 1984

Robins J., When We Dead Awaken. Australia, New Zealand and Armenian Genocide, London-New York 2020, https://doi.org/10.5040/9781838607524

Shemmassian V., The Armenians of Musa Dagh. From Obscurity to Genocide Resistance and Fame 1840-1915, Fresno 2020

The First Armenian Republic (1918-1920) on its Centenary. Politics, Gender and Diplomacy, red. B. Der Matossian, Fresno 2020

\section{Jakub Osiecki, Presentation of chosen 2020 English publications in the field of Armenian studies}

Abstract: The article discusses a few chosen publications in the field of Armenian studies, published in the English language in 2020. It presents the books which were published primarily by the publishing house I.B. Tauris (Bloomsbury Publishing), the American Society for Armenian Studies, as well as by publishing houses Brill and Peter Lang.

Keywords: Armenia, Armenian Studies 


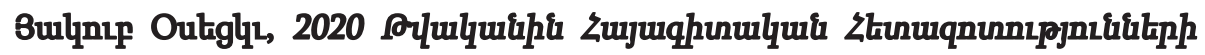

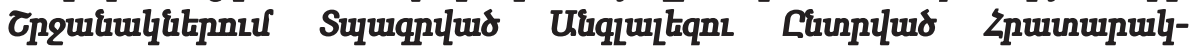
nLPJnLisitph Ulqiuupl

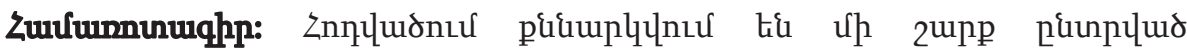

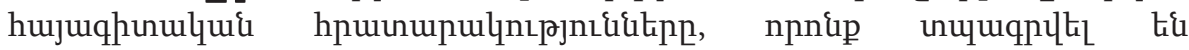

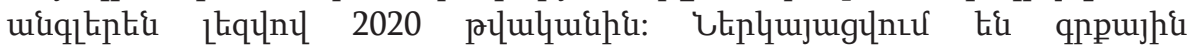

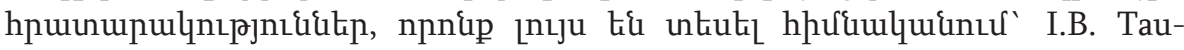
ris (Bloomsbury Publishing) hpuununul $1<n\llcorner p j u i d$, Society for Arme-

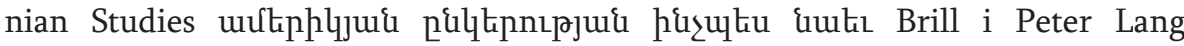
hpuunupulınıpjnı\&itiph lnnưhg:

fulnuwh punntep. Zujuuunui, hujuqhunntpjnı\&: 